Article

\title{
The Body in Grief: Death Investigations, Objections to Autopsy, and the Religious and Cultural 'Other'
}

\section{Belinda Carpenter $^{1, *}$, Gordon Tait ${ }^{2}$ and Carol Quadrelli ${ }^{3}$}

1 School of Justice, Faculty of Law, Queensland University of Technology, 2 George St, Brisbane, Queensland 4001, Australia

2 School of Cultural and Professional Learning, Faculty of Education, Queensland University of Technology, Victoria Park Road, Kelvin Grove, Queensland 4059, Australia;

E-Mail: g.tait@qut.edu.au

3 School of Justice, Faculty of Law, Queensland University of Technology, 2 George St, Brisbane, Queensland 4001, Australia; E-Mail: c.quadrelli@qut.edu.au

* Author to whom correspondence should be addressed; E-Mail: b.carpenter@qut.edu.au; Tel.: +61-7-3138-7111; Fax: +61-7-3138-7123.

Received: 9 January 2014; in revised form: 5 February 2014 / Accepted: 12 February 2014 / Published: 26 February 2014

\begin{abstract}
Sudden, violent and otherwise unexplained deaths are investigated in most western jurisdictions through a Coronial or medico-legal process. A crucial element of such an investigation is the legislative requirement to remove the body for autopsy and other medical interventions, processes which can disrupt traditional religious and cultural grieving practices. While recent legislative changes in an increasing number of jurisdictions allow families to raise objections based on religious and cultural grounds, such concerns can be over-ruled, often exacerbating the trauma and grief of families. Based on funded research which interviews a range of Coronial staff in one Australian jurisdiction, this paper explores the disjuncture between medico-legal discourses, which position the body as corpse, and the rise of more 'therapeutic' discourses which recognise the family's wishes to reposition the body as beloved and lamented.
\end{abstract}

Keywords: body; religion; Indigenous; culture; death; sacred; grief; autopsy; coroner; Australia 


\section{Introduction}

The role of the Coroner (or medico legal officer) is to preside over death investigations where there is a suspicion as to cause of death, a need to identify the deceased, a death of unknown cause or a violent or unnatural death. In more recent times, Coroners have also been required to preside over deaths which occur in institutions, including prisons and aged care facilities. In Australia, and other jurisdictions such as New Zealand, England and Wales, where Coroners are legally trained, they are aided in their investigatory work by police, who visit the scene of the death and gather relevant information, and Pathologists and other medical personnel who perform autopsies and other medical procedures on the deceased. Coroners are responsible for a cause of death certificate being determined and recorded in the Registry of Births Deaths and Marriages [1].

Importantly for the context of this paper, all Coronial (or medico legal) investigations require some form of autopsy once the deceased has been ascertained as a reportable death. Generally speaking, there are two broad categories of autopsy: the hospital or clinical autopsy, and the medico-legal or Coronial autopsy. The capacity to perform any internal investigation on a deceased in the hospital or clinical setting rests on the consent of the relatives of the deceased, while the capacity to perform any internal investigation on the body of the deceased in a Coronial setting is based solely on the Coronial order. In fact, the Coroner is given the right to order an autopsy as part of the death investigation, and may do so irrespective of the wishes of the family [2].

Autopsies generally take three forms: external examination of the body, and/or a partial internal autopsy, and/or a full internal autopsy. While it might be argued that the major role of an autopsy in both the hospital and Coronial setting is largely the same, in that they must both provide the cause and some circumstances of death, it is the issue of family consent (or lack thereof in the Coronial system) that is the central distinction between them. Moreover, the result of an increased focus on consent in the hospital or clinical setting has seen a steep decline in such autopsies since the 1980s while Coronial autopsies have remained constant, or even increased. As a consequence, the vast majority of autopsies performed now occur in the Coronial setting [3].

What is important for this paper is the current legislative requirement, variously enacted in all Australian states, that a family's religious and cultural status and concerns about the autopsy be communicated to the police at the time of the death notification. Those most consistently identified are Indigenous people, and those of Jewish and Muslim faiths. This requires such bereaved families to not only identify themselves to police but to understand and negotiate, in the traumatised state of a sudden bereavement, the medical and legal implications of a challenge to the internal autopsy of a loved one [4]. This is complicated by the fact that the Coroner has the final determination as to whether or not an internal autopsy will proceed and that a family's objection may, despite their strongly held beliefs, be over-ruled.

This involvement of families can be situated as a relatively recent addition to Coronial legislation, influenced by an increasing multicultural awareness and tolerance of difference by public authorities, supported as a last resort through laws against discrimination ([5], p. 10). Embedded in a larger research project on autopsy decision making and interviews with key professionals in the Queensland Coronial system, this paper explores these related ideas, especially the way in which a push toward 
'the wishes of the family' creates a 'dissonance between representing the dead body in medico legal discourse and remembering or memorializing the dead in culture' ([6], p. 42).

\section{Method}

This three year research project is underpinned by a mixed theory and methods approach with action research and participatory frameworks used. The approach has intentionally been highly reflexive, collaboratively engaging with all stakeholders including: industry partners, ethics committees, participants and professional Coronial cohorts to achieve the key deliverable: an e-resource for Coronial professionals. A blend of discourse analysis and thematic analysis informs the theoretical approach providing context to the authentic voices and the lived experience.

Year 1 focused on expert collaboration in the creation of a semi-structured interview template. The initial stage of the research project involved each of the partner investigators identifying the range of issues and problems which occur when a family objection becomes part of a death investigation. A series of meetings with the entire team and one-on-one meetings to clarify issues raised resulted in similarities and differences between each professional group that informed the development of the interview template. Qualitative interview principles including: flexibility and open style, a focus on people's actual experiences and a solid relationship between interviewer and interviewee underpin the interview template. These were in five different formats to engage more closely with the specific duties of each cohort and relating to four themes: knowledge and understanding of minority religions and cultures; role and purpose of the autopsy in the scope of a death investigation; communication between Coronial personnel and with families of the deceased; and the; effect of objection on decision making process.

Years 2 and 3 focused on data collection which included 35 face to face and telephone interviews with 5 Coronial cohorts; verbatim transcriptions of the interviews; and thematic analysis. Thirty five interviews with key Coronial decision-making stakeholders ${ }^{1}$ were undertaken throughout Queensland capturing regional and urban perspectives. Interviews lasted from between one hour and up to 2 hours depending on interruptions, engagement and workloads. Nvivo ${ }^{2}$ and Leximancer ${ }^{3}$ software packages were used to manage all aspects of the project, triangulate data sets and were selected for their specific coding capabilities. Analysis was completed by the two Chief Investigators and the Senior Research Associate and was informed by the series of issues raised in the initial stages with the industry partners.

1 These professional cohorts included: Coroners, Police officers, Forensic pathologists, Coronial counsellors and Coronial nurses.

2 QSR Nvivo 9 is a qualitative data analysis software for qualitative researchers working with rich text based or multimedia information.

3 Leximancer is a text analytics tool that can be used to analyse the content of collections of textual documents and to display the extracted information visually. The information is displayed by means of a conceptual map that provides a complete overview of the material, representing the main concepts contained within the text as well as information about how they are related. 


\section{Religious and Cultural Minorities}

In Australia, Coronial investigations account for $10 \%-15 \%$ of all recorded deaths. Indigenous people tend to be over-represented in Coronial investigations, and Muslim and Jewish populations tend to be under-represented. Moreover, within our research, the identified status and raised objections of Indigenous people tend to have little impact on autopsy decision making, while Jewish and Muslim populations - though both representing complex continua of religious beliefs and affiliations - tend to have less invasive autopsies performed when their status is identified or a concern is communicated to the Coroner [3,7]. This appears to suggest that religion and culture does not impartially inform Coronial staff in their decision making about autopsy and a further discussion of this issue offers some insight as to the differential positioning of religious and cultural minorities in the Coronial system.

\subsection{Islamic Visibility and Suspicion}

... and I've found that Muslims have a tendency to object big time. It's not that I hate Muslims, it's just that they are prominent on the objection side, 'oh, you don't need to do this because you're cutting up the body,' and well hang on, I immediately get suspicious when somebody, 'oh no, you shouldn't, you shouldn't'. What have you had to do with this death in that case? I think we need to look at this a little bit further if you're objecting so strongly, and putting it under the guise of religious or cultural concerns (Police Officer 2).

Obviously when we have Islamic and Jewish deaths then there is a potential for problems there. They almost never consent to autopsy - they have strongly upheld objections and they want the bodies returned to them asap because they have to be buried within 24 hours (Pathologist 4).

When they are concerned it's hard to make them see otherwise, because they've got strong views about it. I mean cultural issues too. We have a lot of Muslims who won't agree, and they're usually just CTs, and also we need to get them out in 24 hours for burial (Coroner 2).

If a Muslim person wasn't objecting I'd be like, 'oh hang on, do you know what's happening here?' And I guess that's just based on my professional knowledge (Counsellor 2).

While the Islamic objection to autopsy appears well known by many Coronial staff, the suspicion perceived in such an objection is also apparent, as is a recognition of devout and hard felt religious positions that may be in opposition to secular legal enquiries. While it is convenient to point to the rising Islamophobia in western nations post 9/11 [8,9], and their increasing visibility in Australia [10], it is also clear that Muslim immigrants have been seen as a problem community since Lebanese Muslims started arriving in Australia in significant numbers from the 1970s ([5], p. 12; [10]). There may be a number of reasons for this. First is the intertwining of religion and politics in Islam and its portrayal as in opposition to secular modernity, which correlates with political disloyalty to Australian national identity. Concerns over 'Muslim first and Australian second', speak to the 'underlying expectation that all immigrants are on the journey to becoming Australian, at least across generations' ([5], p. 12). Second, is the focus on the cultural incompatibility of Islam to the West that is positioned as a cultural backwardness rather than just a cultural difference, and particularly in terms of their control and treatment of women. Such an understanding constructs Muslims as 'trapped by tradition' in contrast to the West, which is 'liberated from cultural constraints and individually autonomous' ([5], p. 21). 
Finally, the more recent moral panic around terrorism has led to a situation 'where any expression of Islamic religious identity is suspicious', possibly indicative of an underlying and dangerous fundamentalism ([5], p. 13). This has led to the creation of 'suspect communities' who should be 'monitored by state agencies, casting new questions about citizenship, identity and loyalty' ([8], p. 211). Such an understanding is now widespread in Australian society with the 'Arab other' constructed through a 'complex process involving recurrent negative media portrayals, prejudiced political pronouncements and racist populist rhetoric' ([11], p. 366).

\subsection{Judaism and Advocacy}

There is a liaison for the Jewish community. I think there is also for the Samoans, and so on, through the Church. But they're less proactive than the Jewish community. I think there's a liaison fellow from the Jewish community, and he'll get involved pretty quickly. It's really just to ensure that the burial takes place as soon as possible. That's not necessarily an objection to autopsy. I don't think they mind autopsy so much, but it's got to be done quickly (Coroner 4).

He's very much an advocate for the Jewish community in New South Wales, and by default, now all of Australia, who was very, very active in issues of objections to autopsies, objections to retention of tissues, and was very active in changing initially, the way that the New South Wales Government operated and ultimately, the law (Pathologist 2).

Despite the similarities between Judaism and Islam in terms of Coronial understanding of the religious legitimacy of their objection, the differences between the situation of Jewish advocacy and that of Muslin suspicion and visibility is stark and speaks to the different space that the Jewish community occupy in Australian society [12,13]. Part of the reason for this, according to Stratton [14] is that the 'Jew' is understood as a socially constructed 'gentile, Western Other', homogenized and othered in much the same way as the 'Asian', but not to the same extent because the Jew is also white, European and Western. It is also consistently noted that prominent members of the Jewish community were part of the founding government of Australia, and continued to use their influence in policy and legislation regarding Jewish immigration after WWII [15]. Research also demonstrates that anti-Semitism is on the decrease in Australia, unlike many other countries [15,16] and that the Jewish community are neither over-policed nor over-criminalized in Australia [16]. Finally, the recasting of Judaism after the Holocaust as integral to the history of the West would appear to place Jewish objections against autopsy in a different location to either Muslim or Indigenous concerns [17].

\subsection{Indigenous Invisibility}

But interestingly we rarely have many issues concerning autopsies within the Aboriginal community and we should do, there should be more and I don't know why. Now it could be that it's more of an urban population, and therefore it's not a particular issue for them, or it could be that no-one's asking the questions (Coroner 1).

I would expect that more often than not Indigenous communities didn't understand what their options were, and more often than not-you know—subjugated springs to mind. They just went along with what the police and authority figures have always told them (Coroner 8). 
There's a fair few aboriginal autopsies that we do as well, and there's never any sort of problems getting permission for those because they don't have a problem with having an autopsy. There's never been any protestation. Very occasionally..... (Pathologist 1).

Unlike Muslim suspicion or Jewish advocacy, it appears that Indigenous objections are all but invisible in the Queensland Coronial system. There may be a number of reasons for this. First, there is a long and well documented history of poor relations between police and Indigenous people, including 'volatile conflict' and 'police abuse and harassment', 'excessive force' and 'institutional racism' [18], which may mean that Indigenous people do not wish to have their cultural identity known to police. Second, given the over-representation of Indigenous people in the criminal justice system-also well documented-it may be that if their cultural identity is known, this is through adverse dealings with police and magistrates. In such a context, Indigenous people may feel powerless to have their objections heard, which is particularly unfortunate given Indigenous over-representation in the Coronial system, due in part to such structural factors as endemic violence, poor access to health care, low life expectancies and high rates of chronic disease [7]. Ironically, the silence and invisibility of the Indigenous community occurs against a backdrop of 'the endemic losses of colonialism and the heightened mortality of ongoing alienation', and which in other contexts, such as Maori in New Zealand, have been argued to increase, rather than decrease, the relevance of cultural practices in relation to loss and death ([19], p. 27).

These disclosures from Coronial staff and their social and historical context, serve as the background to a discussion of how Coronial staff manage the grief associated with a death that comes to be investigated by the Coronial system. The little research there is on families dealings with a Coronial death suggest that Coronial processes can cause further trauma to family members already suffering significant grief [4,19,20-23]. While this has been noted in particular during the inquest [20,22], in the scandals relating to the retention of organs [4,23] and experimentation on bodies [24], it is most keenly felt in the commonplace (and legislative necessity) of autopsy, where terms such as 'mutilation', 'desecration', and 'barbaric acts' have been used by families to describe images of the autopsy of their loved one ([23], p. 41). The next section of this paper pays particular attention to the differing ways in which Coronial staff understand and negotiate the trauma and grief of a death investigation.

\section{Grief Work}

The ways in which Coronial staff engage with families during a death investigation-from both religious and cultural minorities, and otherwise-has the potential to either minimise or exacerbate the pain and suffering of a sudden death. Certainly Coroners seem acutely aware of this in the context of suicide determinations and acknowledge that their findings are often informed by the distress of the family in an inquest [25]. Unfortunately, in the context of a death investigation, families are often asked to make important decisions when still in the grip of the shock and disbelief of the death notification. It is well recognized that this impacts on the decision making capacity of families, given their severely compromised ability to process and retain complex information at that time ([4], p. 238). Coronial staff certainly understand this and wrestle with the ethical implications of decision making in such a context [26]. 
In the immediate aftermath of bereavement, cognitive function is that of an 8 year old. So that's just normal bereavements-if you are taking on traumatic bereavement as well, we're actually asking people that have very reduced cognitive function to make really important decisions. So the short answer is that you can't be assured that they understand, you can't actually have any confidence that people know what they are agreeing to (Counselor 2).

Most people are in shock. They won't even remember the conversations they've had with you... how well do you reckon they process that question [about autopsy] and how familiar are they do you think with the autopsy process? (Police Officer 4).

Part of the problem, as recognized by these staff, is that in a death investigation, grief is compounded by trauma, and there is a general consensus that the trauma of a violent or unexpected death 'poses specific and daunting challenges which do not necessarily follow a non-traumatic death' ([4], p. 233). Coronial professionals cope with the emotional distress of families in different ways depending upon their training and background. Pathologists and Coroners for example, tend to ensure a certain distance from the families in order to maintain their professional objectivity.

I tend to keep a distance. Different people do different things ... there's still an emotional involvement that you have to manage and you have to manage your own capacity to rationally make decisions in accordance with legislation while balancing emotional involvement. And to some extent you have to be protective of yourself to be able to do that properly (Coroner 3).

... but we don't tend to have really much to do with the families. In a sense I actually think that's a good thing; it helps to maintain our objectivity which I think is really essential in our component of the job, because to get caught up in the emotional turmoil of what families are going through I think can color your judgment in terms of your approach and how you reason through particular cases (Pathologist 4).

This notion of objectivity forms one of the central pillars within the logic of modernity, and the new forms of expertise that developed within it have succeeded, in large part, because of the status of the truth claims they produce which 'operate on the basis of detachment' ([27], p. 8). As Kramar ([28], p. 803) notes, both pathologists and Coroners are presented as offering 'disinterested' facts about a death 'advanced purely for [their] inherent value in assisting the truth seeking element of the process.' However, these disclosures from legally and medically trained staff also indicate how the emotion of death plays a part in their decision to detach themselves from families, and how potentially challenging suffering, bereavement and loss can be to medical and legal practice. Most quickly delegate this grief work to the counselors to navigate and rely upon them to act as a conduit between the discursive space of law, medicine and loss.

In contrast, police and counselors find themselves in close quarters with grieving and bereaved families given that police deliver the death notification and investigate the death on behalf of the Coroner, while counselors assist the Coroner in any communication the family may have about autopsy, organ retention and timely release of the body. These two groups however also demonstrate the difficulties of dealing with traumatized families and how such investigations challenge their professional experience and training. 
Dealing with people who are suddenly thrust into a grieving process is totally different from dealing with somebody who's had their house broken into or somebody who was drunk and belligerent (Police Officer 2).

It's just a contentious issue it's a thing that police don't like to do ... we're not counselors (Police Officer 1).

While such admissions may not be wholly surprising from police, who are not trained in dealing with bereaved families, there is also a challenge for counselors who are specifically included in a death investigation because of their professional knowledge on bereavement, demonstrates the particular difficulties raised in a Coronial death investigation. As Drayton ([4], p. 238) identifies, 'as social welfare professionals, the counselors work within an ethical framework which asserts the centrality of client self-determination.' In a death investigation, this capacity is compromised by the powerlessness of families and counselors who are both removed from any real decision making [26].

People don't read the stuff they're given at the time of bereavement because they can't even concentrate long enough to read a few points (Counselor 1).

It's just support around the lack of power they have in the system which is highlighted more when there is an objection to autopsy. They don't have access to the body. It's very disempowering (Counselor 5).

There's one particular Coroner who's not interested in why people object. He contacts us and he says, 'you contact them and tell them that the Coroner has overruled their objection' and we'll go, 'but the Coroner doesn't know what the objection is about yet'. So you're basically telling them that the Coroner has overruled their objection without them having the opportunity to say to the Coroner what their objection is based on. He's probably legally within grounds to do it, but I think it's just a distasteful way of managing what's quite a distressing and difficult time for people (Counselor 4).

Such powerlessness is exacerbated for families from cultural and religious minorities when a death investigation interrupts culturally specific grieving practices, many of which focus on the presence of a body $[19,29,30]$. In a Coronial death investigation, bodies must be removed to a state morgue for investigation and autopsy. Even if families successfully negotiate an objection to an internal autopsy of their loved one, an external autopsy of the body by a pathologist is still required, often with the extraction of blood and urine for toxicology. This can mean that funerals are delayed, bodies are absent and mourning rituals are interrupted. The rest of this paper engages with this idea, specifically that there is a dissonance between the requirements of a medico-legal autopsy to seek the truth of the death in the information contained in the body, and the continuing familial connection to the body of the deceased as a personification of the spirit or the soul of their loved one.

\section{Autopsies}

As previously noted, autopsies are a legislative requirement of a Coronial or medico-legal investigation into a death, and they do not require the consent of the family to proceed. Legislation however allows the Coroner to determine the level of invasiveness of an autopsy, with many Coroners confirming the importance of a raised family objection on their decision making.

The family's wishes must be observed. You just don't chop people up for the pleasure of satisfying some forensic curiosity that may exist in the pathologists or somebody else's mind. You have to really satisfy the needs of the family in relation to the deceased. They're paramount (Coroner 5). 
But if they have an objection which is expressed fairly strongly ... [and] we discuss all those objections with the family and it stills comes back with an objection, and that's their final position, then I'm unlikely to overturn their objection. I personally am almost never going to overturn their objection in a non-suspicious case even when the cause of death is going to be undetermined (Coroner 1).

Such strong support for the wishes of the family in autopsy decision making has been discussed by the authors as exemplifying the rise of therapeutic jurisprudence in a Coronial investigation [31]. However, it is also in a context of very few objections being raised, especially by those with religious or cultural proscriptions against autopsy [3]. In general, such proscriptions position the body as sacred, as a holy vessel belonging to God after death [13]. There is a clear concern about the close proximity of the soul to the body immediately after death [32]. It is also believed that dissection of the body can be perceived as painful to the soul and the body, as well as interrupting the soul's journey to an afterlife $[33,34]$. For these reasons, objections based on cultural and religious identity seem to carry more weight for Coronial staff.

I think religious and cultural affiliation has to be taken into account no matter what and some Coroners are better than others in acknowledging that. And I think it's just so important and I see the fallout of what happens if people aren't heard, and you know if someone has a really strong objection because of religion and I can come back and explain why it has to happen regardless of that, they can accept that, whereas if they're not heard it's like an assault on their belief. And that's an added trauma to them (Counselor 2).

But the family did say no we don't want him touched, and we have to bury him as soon as possible, we want to do it tomorrow morning ...So I didn't order an autopsy at all in that case, and that's my practice to do that (Coroner 9).

..with some groups where there was a need to bury before sunset we would expedite everything. So I would bend over backwards to accommodate as much as possible the needs of the different faiths (Coroner 8).

However, this is not to argue that all Coronial professionals are in agreement as to the pre-eminence of the family's views when decisions about autopsy are made. Pathologists and police are the most vocal in challenging their importance.

I think we shouldn't sanction cultural and religious views as much as we do. I don't like to use the word superstitious, I don't think we're allowed to, but views which are not based on any tangible evidence are given too much weight in the current process in my opinion. I would like to see less reliance or less ability for families to successfully not have their relative subjected to an autopsy on the basis of cultural or religious views. Is that fair, possibly not, I don't know (Pathologist 4).

The religious aspect and the cultural aspect should not influence it. What should influence it is the inquisitional element of getting to the truth of that death. I mean, God, if I was wanting to get rid of somebody I'd be kicking up hell and saying oh no it's against my religious beliefs. Very hard to prove someone's been killed if you've got rid of them (Police Officer 2).

It is perhaps not surprising that the pathologists in this study stand in opposition to what they perceive as this recent impost on the process of a death investigation-wedded as they are to science as the point of access for the truth of the death [35]. However, positioning religious beliefs as superstitious not only ignores the historical relation between community standards and Christian values [12] but 
also the social and historical construction of their own medical claims to truth. What may be more curious is the diametrically opposed position of police and Coroners to the introduction of familial beliefs-who are both legal officers of the court and yet who offer either resentment or respect to the idea. In such conversations, it is argued that two competing representations of the dead body are evident: the medico-legal body which is 'mechanistic', 'devoid of personality', 'tissue'; and the body as 'beloved and lamented' ([4], p. 240). For medical officers and increasingly for police, where popular culture valorizes scientific investigations, and particularly autopsy, as core business-consider the popularity of television programs like CSI — the body and its organs, tissues and cells are evidence of the cause of death. They are a 'container of knowledge,' offering information through observable facts 'which may be literally seen, held and measured' ([26], p. 266). For police in particular, and for many forensic pathologists, ruling out any suspicion of 'foul play' is crucial and reason enough for a thorough dissection of the body. The cause of death and the ultimate truth of the disease is thus to be found in the body which presents as an object to be examined.

I've said well we've got the staff, we get changed, we're in the autopsy room and it's no difference to us [whether we perform an internal or an external autopsy] Because we get the thing bloodied and we have to clean the thing away and we've got resources to do it ... I'm a medical person it's no big deal to me. I don't lose any sleep over opening a body (Pathologist 1).

I like to do my job properly, so if I think someone needs a full internal examination and brain retention, I will pursue that option regardless (Pathologist 5).

For the family, a continuing connection to the body has been argued to be a normal part of suffering, grief and loss ([4], p. 231) but intensified during a Coronial death investigation due to the shock of a Coronial death [36]. The dead body maintains a 'social existence as a powerful representation of the self' ([37], p. 56), which is not immediately removed at death. Such connections are based on memories of the deceased in life, which are necessarily associated with their body in death. While it is recognized that the body is empty, 'a corpse', it is also the case that the body maintains a social identity as manifestation of their loved one. As a consequence, Coronial staff are able to empathize with the position of families, irrespective of and at times in contradiction to, their professional training.

When my mother died I didn't want her violated...I don't see why after a certain age we have to go chopping up old people to establish cause of death (Coroner 5).

I think that the majority feel that their loved one has been through enough and don't want him cut up anymore. I can understand that I don't make judgments. They're entitled to their position and think my own position would be — god forbid it should happen to any of my family—but if that situation did present itself I probably wouldn't want them cut up either (Pathologist 5).

I knew what had happened-it was a heart attack. I would have objected to my own father undergoing an autopsy because it was obvious as to what had happened to him (Coroner 4).

It is clear that such emotional attachment is to the body of the deceased, with the Coronial system exerting considerable influence on how the body is to be accessed and treated. Many families feel alienated and disenfranchised by not being able to stay with the deceased and the resultant medicalization 
and certification of death in the Coronial system makes it difficult to observe traditions and obligations for certain religious and cultural communities. However, now that all Coronial legislation stresses 'the rights of the family member to be involved in decisions concerning the deceased' ([38], Section 1.1), it is increasingly being suggested that the Coronial system, especially a Coroner's work, is intimately connected with 'well being' and thus fits squarely within the ambit of therapeutic jurisprudence [39]. While commentators are quick to point out that therapeutic values should not outweigh procedural fairness requirements [40,41] it is also acknowledged that sensitivity, clear communication, access to counseling and support and opportunities for families to express their distress and grief are crucial to an acknowledgement of their loss and the humanity of their loved one [42]. This may be especially the case for those whose religious and cultural beliefs sit outside modernist notions of the body as a medical object of enquiry. While we have argued elsewhere [35] that the central debate within the Coronial jurisdiction is between the pillars of law and medicine, it also seems likely that the bereaved views in relation to autopsy introduce a third discourse into the debate-'knowledge born of emotional attachment' or 'suffering' ([4], p. 236), and that this is gaining ground in Coronial investigations, especially where religious beliefs are concerned.

\section{Conclusions}

The introduction of bereaved family's views into the medico-legal death investigation has added three central tensions to the process. The first is the different spaces occupied by the families, depending on their cultural or religious location in larger social and historical processes. It is clear that wider fears over Islamic fundamentalism post 9/11 have influenced suspicion in the minds of some Coronial personnel, while Jewish political and social influence has been used to advocate more successfully for bereaved families. The silence and invisibility of Indigenous beliefs and concerns speaks to their ambiguous position in a Coronial investigation often overseen by personnel who also act in the criminal justice space.

Second, these conflicting and contradictory engagements with bereaved families who have legitimate reasons for objecting to an autopsy is compounded by the nature of a reportable death-unexpected and often violent-and the ways in which Coronial procedures disrupt traditional grieving practices. Specifically, it is the differing ways in which the dead body is perceived-corpse or beloved—and its forced removal for the purpose of the medico-legal process of death investigation that is most often cited as the cause of suffering and pain for the family. This is compounded by the role of police in the investigation of Coronial deaths, which has been highlighted as particularly traumatic for those families who are part of communities already over-policed and over-criminalized.

Finally, the differences between Coronial personnel's attitudes to the role and place of families suffering through a medico-legal investigation, has indicated the importance placed by Coroners on the relation between their role in the prevention of avoidable deaths and the therapeutic potential of a death investigation for families. As the primary decision makers in a Coronial death investigation, this convergence has the potential to undermine more traditional knowledge like science and medicine as the final arbiters in a death investigation. CSI not withstanding, it appears that a discourse of emotion and suffering may be on the verge of entering the medico-legal space of a Coronial investigation. 


\section{Acknowledgements}

This research is funded by the Australian Research Council Linkage scheme and the Queensland Department of Health. It is a collaborative project with in kind support from industry partners including Queensland Health Forensic Scientific Services, Queensland Police and the State Coroner's Office through the Office of Attorney General. It is led by QUT researchers from the Faculties of Law and Education.

\section{Author Contributions}

All authors contributed equally to this article.

\section{Conflicts of Interest}

The authors declare no conflict of interest.

\section{References and Notes}

1. Barnes, Michael, and Belinda Carpenter. "Reliance on Internal Autopsies in Coronial investigations: A review of the issues." Journal of Law and Medicine 19, no. 1 (2011): 88-100.

2. Carpenter, Belinda, Michael Barnes, Charles Naylor, Glenda Adkins, and Brendan White. "Issues surrounding a reduction in the use of internal autopsy in the coronial system." Journal of Law and Medicine 14, no. 2 (2006): 199-208.

3. Carpenter, Belinda, Gordon Tait, Glenda Adkins, Michael Barnes, Charles Naylor, and Nelufa Begum. "Communicating with the coroner: How religion, culture, and family concerns may influence autopsy decision making." Death Studies 35, no. 4 (2011): 316-37.

4. Drayton, John. "Organ retention and bereavement: Family counselling and the ethics of consultation." Ethics and Social Welfare 5, no. 3 (2011): 227-46.

5. Humphrey, Michael. "Culturalising the abject: Islam, law and moral panic in the West." Australian Journal of Social Issues 42, no. 1 (2007): 9-25.

6. Scott Bray, Rebecca. "Fugitive Performances of death and injury". Law Text Culture 10 (2006): 41-71.

7. Carpenter, Belinda, and Gordon Tait. "Death, health and indigenous australians in the queensland coronial system.” Australian Aboriginal Studies, no. 1 (2009): 29-41.

8. Spalek, Basia. "Muslim Communities post 9/11-Citizenship, security and justice." International Journal of Law, Crime and Justice 36, no. 4 (2008): 211-14.

9. Poynting, Scott, and Victoria Mason. "Tolerance, freedom, justice and peace?: Britain, Australia and anti-muslim racism since 11 September 2001." Journal of Intercultural Studies 27, no. 4 (2006): 365-91.

10. Poynting, Scott, and Victoria Mason. "The resistable rise of Islamophobia: Anti-Muslim racism in the UK and Australia before 11 September 2001." Journal of Sociology 43, no. 1 (2007): 61-86.

11. White, Rob. "Ethnic diversity and differential policing in australia: The good, the bad and the ugly.” International Migration and Integration 10, no. 4 (2009): 359-75. 
12. Coleman, Elizabeth Burns, and Kevin White. "Negotiating the Sacred in Multicultural Societies." In Negotiating the Sacred: Blasphemy and Sacrilege in a Multicultural Society. Edited by Elizabeth Burns Coleman and Kevin White. Canberra ACT: ANU Electronic Press, 2006. Available online: http://epress.anu.edu.au?p=35161 (accessed on 12 November 2013).

13. Ritchie, David. "Space and Loss: Spirituality and symbolic connectedness in contemporary culture." Double dialogues 7, winter 2007, 1-9.

14. Stratton, Jon. Coming Out Jewish. London: Routledge, 2000.

15. Rutland, Suzanne D. The Jews in Australia. Melbourne: Cambridge University Press, 2005.

16. Stobbs, Nigel. “Australia.” In Racist Victimisation: International Reflections and Perspectives. Edited by John Winterdyk and Georgios A. Antonopoulis. Aldershot, UK and USA: Ashgate Publishing, 2008, pp. 19-42.

17. Mamdani, Mahmood. Good Muslim, Bad Muslim: America, the Cold War, and the Roots of Terrorism. New York: Pantheon, 2004.

18. Cunneen, Chris. "Aboriginal deaths in custody: A continuing systematic abuse." Social Justice 33, no. 4 (2006): 37-51.

19. Eileen Clarke, and Tim McCreanor. "He wahine tangi tikapa ...: Statutory investigative processes and the grieving of Maori families who have lost a baby to SIDS." Kotuitui: New Zealand Journal of Social Sciences Online 1, no. 1 (2006): 25-43.

20. Green, Judith. "The medico-legal production of fatal accidents." Sociology of Health \& Illness 14, no. 3 (1992): 373-89.

21. Harwood, Daniel, Keith Hawton, Tony Hope, and Robin Jacoby. "The grief experiences and needs of bereaved relatives and friends of older people dying through suicide: A descriptive and case-control study." Journal of Affective Disorders 72, no. 2 (2002): 185-94.

22. Biddle, Lucy. "Public hazards or private tragedies? An exploratory study of the effect of coroners' procedures on those bereaved by suicide." Social Science \& Medicine 56, no. 5 (2003): 1033-45.

23. Robb, Barbara, and Jane Sullivan. "The past and the present: Listening to parental experiences of autopsy practice." Grief Matters: The Australian Journal of Grief and Bereavement 7, no. 2 (2004): 39.

24. Walker, Bret. Inquiry into Matters Arising from the Post-Mortem and Anatomical Examination Practices of the Institute of Forensic Medicine: Report. Sydney: State Government Publishing, NSW Department of Health, 2001.

25. Tait, Gordon, and Belinda Carpenter. "Suicide and the therapeutic coroner: Inquests, governance and the grieving family." International Journal for Crime, Justice and Social Democracy 2, no. 3 (2013): 92-104.

26. Drayton, John. "Bodies-in-life/bodies-in-death: Social work, coronial autopsies and the bonds of identity. British Journal of Social Work 43 (2013): 264-81.

27. Burney, Ian A. Bodies of Evidence: Medicine and the Politics of the English Inquest, 1830-1926. Baltimore: JHU Press, 2000.

28. Kramar, Kirsten. "Coroners' interested advocacy: Understanding wrongful accusations and convictions." Canadian Journal of Criminology and Criminal Justice/La Revue canadienne de criminologie et de justice pénale 48, no. 5 (2006): 803-22. 
29. Tatz, Colin. Aboriginal Suicide is Different. Canberra: Aboriginal Studies Press, 2005.

30. Byard, Roger W., and Wayne C. Chivell. "The interaction of death, sorcery and coronial/forensic practices within traditional indigenous communities." Journal of Clinical Forensic Medicine 12, no. 5 (2005): 242-44.

31. Carpenter, Belinda, Gordon Tait, and Carol Quadrelli. "Arguing the Autopsy: Mutual Suspicion, Jurisdictional Confusion and the Socially Marginal." In Crime, Justice and Social Democracy: Proceedings of the 2nd International Conference 2013, Volume 1. Edited by Kelly Richards and Juan Tauri. Brisbane: Crime and Justice Research Centre, QUT, 2013, pp. 10-18. http://crimejusticeconference.com/wp-content/uploads/2012/05/Conference-Proceedings_Vol1_2013.pdf.

32. Al-Adnani, Mohammed. "Personal view: How can we improve the rate of autopsies amongst Muslims?" British Medical Journal 332 (2006): 310.

33. Gatrad, Abdul Rashid. "Muslim customs surrounding death, bereavement, post-mortem examinations, and organ transplants." British Medical Journal 309 (1994): 521-23.

34. Campbell, Courtney S. "Religion and the body in medical research." Kennedy Institute of Ethics Journal 8, no. 3 (1998): 275-305.

35. Carpenter, Belinda, and Gordon Tait. "The Autopsy imperative: Medicine, law, and the coronial investigation." Journal of Medical Humanities 31, no. 3 (2010): 205-21.

36. Neria, Yuval, and Brett T. Litz. "Bereavement by traumatic means: The complex synergy of trauma and grief." Journal of Loss and Trauma 9, no. 1 (2004): 73-87.

37. Hockey, Jenny. "Encountering the'reality of death'through professional discourses: The matter of materiality." Mortality 1, no. 1 (1996): 45-60.

38. Barnes, Michael. "Queensland State Coroner's Guidelines." Queensland Coroners Court, 2003. Available online: http://www.courts.qld.gov.au (accessed on 30 July 2012).

39. King, Michael S. "Non-adversarial justice and the Coroner's court: A proposed therapeutic, restorative, problem solving model." Research Paper no 2009/30; Melbourne: Faculty of Law, Monash University, 2009. Available online: http://ssrn.com/abstract+no.1599339 (accessed on 16 September 2013).

40. Wexler, David., and Bruce J. Winick. Law in a Therapeutic Key: Developments in Therapeutic Jurisprudence. Durham, NC: Carolina Academic Press, 1996.

41. Winick, Bruce J., and David B. Wexler. Judging in a Therapeutic Key: Therapeutic Jurisprudence and the Courts. Durham, North Carolina: Carolina Academic Press, 2003.

42. Freckelton, Ian. "Death investigation, the coroner and therapeutic jurisprudence." Journal of Law and Medicine 15 (2007): 242.

(C) 2014 by the authors; licensee MDPI, Basel, Switzerland. This article is an open access article distributed under the terms and conditions of the Creative Commons Attribution license (http://creativecommons.org/licenses/by/3.0/). 